\title{
Using PsyScope to conduct IAT experiments on Macintosh computers
}

\author{
Jennifer L. S. Borton, Mark A. OAKes, Margaret E. Van Wyk, And Tyler A. Zink \\ Hamilton College, Clinton, New York
}

\begin{abstract}
The Implicit Association Test (IAT; Greenwald, McGhee, \& Schwartz, 1998) is one of the most widely used tools for assessing implicit attitudes. To date, most IAT experiments have been run using Inquisit, a PC-based program. In the present article, we describe a method for conducting IAT experiments using PsyScope, a free, downloadable, Macintosh-based program (see Bonatti, n.d., for the OS X version; Cohen, MacWhinney, Flatt, \& Provost, 1993, for the OS 9 version). In addition, we explain how data can be imported into SPSS for analysis. Preliminary results indicate that, in comparison with the PC version of the IAT, the Macintosh version provides similar sensitivity in measuring implicit self-esteem. Our PsyScope script and SPSS syntax may be downloaded from www.psychonomic.org/archive.
\end{abstract}

The Implicit Association Test (IAT; Greenwald, McGhee, \& Schwartz, 1998) was developed to assess implicit attitudes, such as stereotypes held about groups (e.g., African Americans), by measuring the strength of automatic associations between different categories (e.g., Black vs. White) and positive or negative words. For example, on the Black-White IAT, participants use a single key to categorize words related to White people and positive words and a different key to categorize words related to Black people and negative words (White + positive/Black + negative). In a later stage, these tasks are reversed, with one key for White and negative words and a different key for Black and positive words (White + negative/Black + positive). Typically, participants take less time when positive attributes are paired with White rather than Black, indicating an implicit preference for White people over Black people. The IAT score is computed by taking the difference of the mean reaction times to the two test stages.

The IAT has generated hundreds of studies (see Greenwald \& Nosek, 2001, for a review) and has been used to assess a wide variety of implicit attitudes, such as those about racial groups (Dasgupta, McGhee, Greenwald, \& Banaji, 2000; McConnell \& Leibold, 2001; Ottaway, Hayden, \& Oakes, 2001), older people (Jelenec \& Steffens, 2002; Rudman, Greenwald, Mellott, \& Schwartz, 1999), obese people (Chambliss, Finley, \& Blair, 2004; Teachman, Gapinski, Brownell, Rawlins, \& Jeyaram, 2003; Wang, Brownell, \& Wadden, 2004), gay people (Banse, Seise, \& Zerbes, 2001), religious groups (Rowatt, Franklin, \& Cotton, 2005; Rudman et al., 1999), and people of various nationalities (Gawronski, 2002). The IAT has also been used to assess individuals' levels of implicit self-esteem (Greenwald \& Farnham, 2000).
The primary program used to run IAT experiments is Inquisit from Millisecond Software (www.millisecond .com), which runs only on the PC platform. To our knowledge, there are currently no versions of the IAT available for Macintosh computers. The purpose of this article is to describe a version of the Self-Esteem IAT created for PsyScope, a free, downloadable, Macintosh-compatible program (see Bonatti, n.d., psy.ck.sissa.it, for the OS X version; Cohen, MacWhinney, Flatt, \& Provost, 1993, psyscope.psy.cmu.edu, for the OS 9 version).

\section{Implicit Self-Esteem}

As noted above, one type of implicit attitude assessed via the IAT is implicit self-esteem (Greenwald \& Farnham, 2000; Karpinski, 2004; Pinter \& Greenwald, 2005), which is a type of unconscious self-evaluation. Implicit self-esteem is distinct from explicit self-esteem (conscious self-evaluation), which is typically assessed via self-report measures. Correlations between implicit and explicit measures of self-esteem are generally positive, but small (Farnham, Greenwald, \& Banaji, 1999; Greenwald \& Farnham, 2000), indicating that, although the two measures overlap, they are different constructs. Implicit and explicit self-esteem have been shown to predict different variables. For instance, implicit self-esteem better predicts nonverbal behaviors indicative of anxiety (Spalding \& Hardin, 2000) and negative affect following threatening feedback (Greenwald \& Farnham, 2000). Other research has shown that measuring both implicit and explicit selfesteem may be necessary for predicting certain patterns of behavior. For instance, in comparison with those having other patterns of self-esteem, individuals with a combination of high explicit and low implicit self-esteem (so-called

J. L. S. Borton, jborton@hamilton.edu 
Table 1

Sequence of Blocks for the Self-Esteem IAT (Counterbalancing Order A)

\begin{tabular}{llll}
\hline \multicolumn{1}{c}{ Block } & \multicolumn{1}{c}{$\begin{array}{c}\text { Categories for } \\
\text { "d" Key }\end{array}$} & \multicolumn{1}{c}{$\begin{array}{c}\text { Categories for } \\
\text { "k" Key }\end{array}$} & \multicolumn{1}{c}{ Number of Trials } \\
\hline $\begin{array}{l}\text { 1. Single categorization of tar- } \\
\text { get word (practice) }\end{array}$ & Self & Other & 24 (Trials 3-26) \\
$\begin{array}{l}\text { 2. Single categorization of at- } \\
\text { tribute word (practice) }\end{array}$ & Positive & Negative & 24 (Trials 28-51) \\
$\begin{array}{l}\text { 3. Combined categorization } \\
\text { (practice) }\end{array}$ & Self or Positive & Other or Negative & 24 (Trials 53-76) \\
$\begin{array}{l}\text { 4. Combined categorization } \\
\text { (test) }\end{array}$ & Self or Positive & Other or Negative & 40 (Trials 78-117) \\
$\begin{array}{l}\text { 5. Single categorization of tar- } \\
\text { get word (reversed) }\end{array}$ & Other & Self & 36 (Trials 119-154) \\
$\begin{array}{l}\text { 6. Combined categorization } \\
\text { (practice, reversed) }\end{array}$ & Self or Negative & Other or Positive & 24 (Trials 156-179) \\
$\begin{array}{l}\text { 7. Combined categorization } \\
\text { (test, reversed) }\end{array}$ & Self or Negative & Other or Positive & 40 (Trials 181-220) \\
\hline
\end{tabular}

Note-Self/Other words are presented in uppercase text; Positive/Negative words are presented in lowercase. The crucial blocks are 4 and 7; the difference of the mean RTs in these two blocks constitutes the IAT score. To counterbalance the combined categorization tasks (Script Variant B), the blocks would be presented in the following order: 5, 2, 6, 7, 1, 3, and 4, with 24 practice trials for Block 5 and 36 for Block 1. The first trial of the first block begins at 3 because of two instructional screens that serve as Trials 1 and 2 .

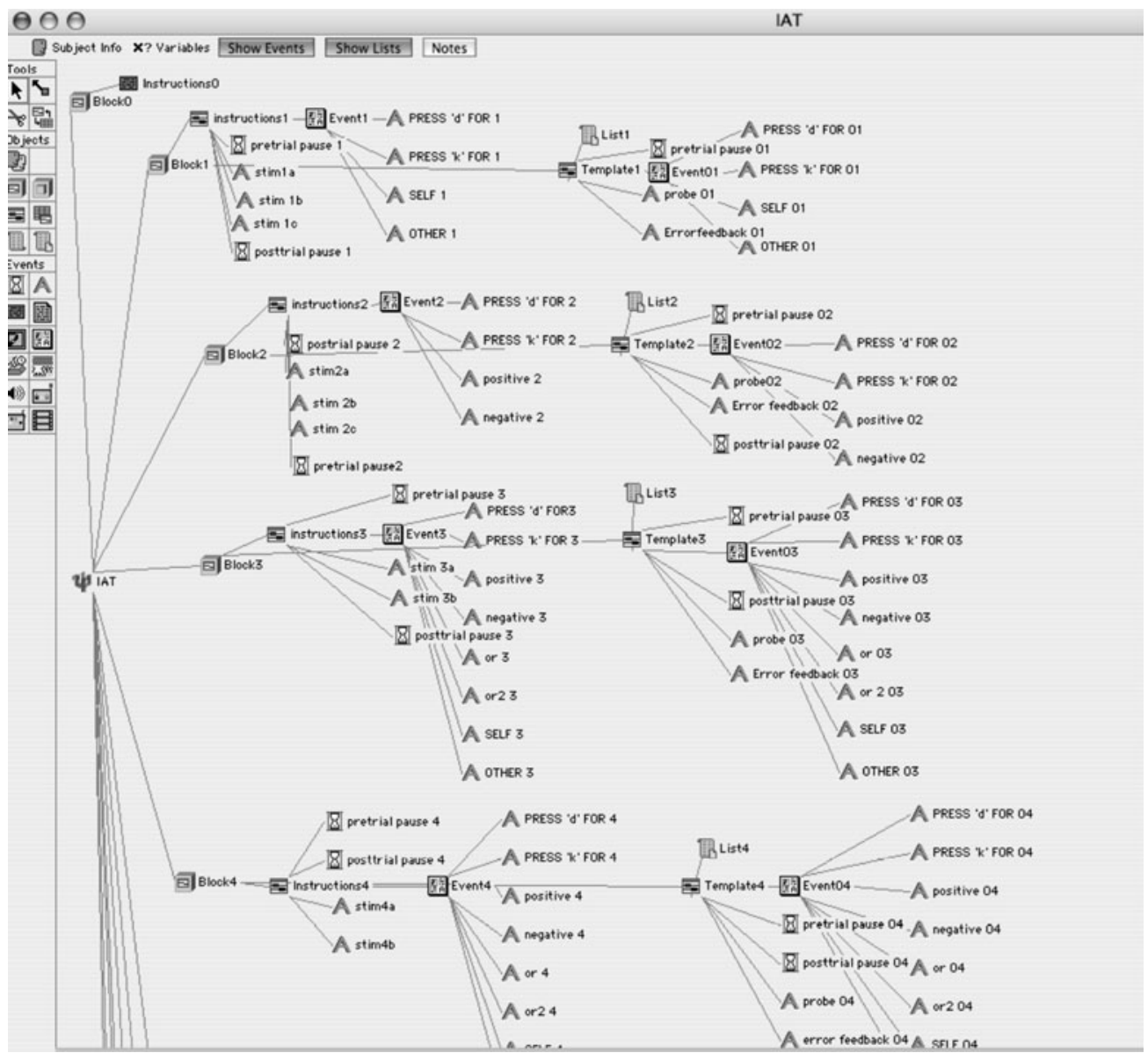

Figure 1. General appearance of the first several IAT blocks in PsyScope's Design window. 


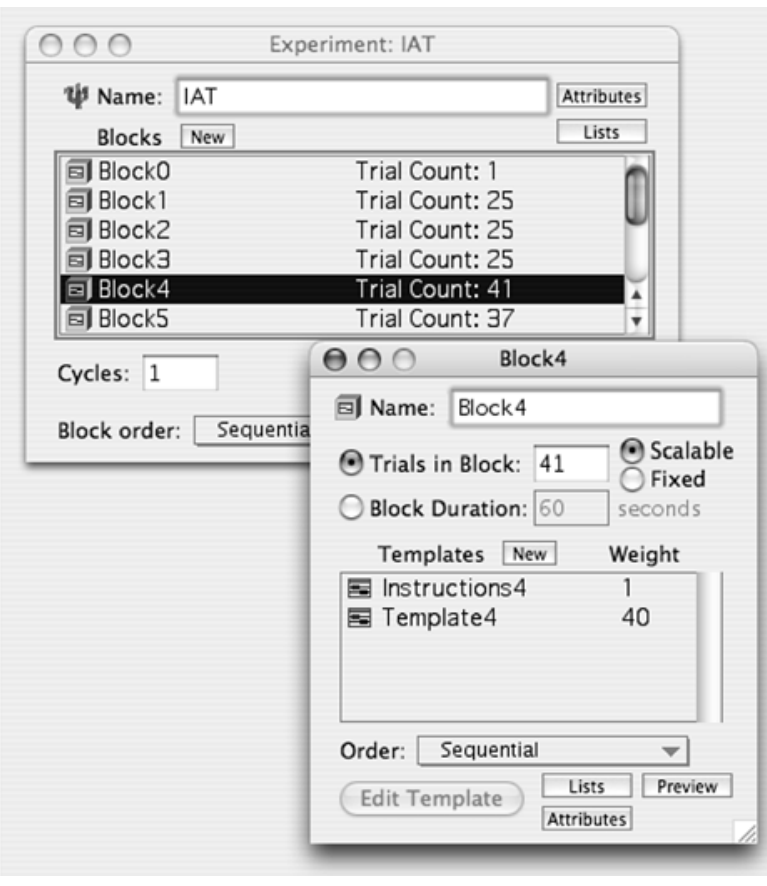

Figure 2. From back to front: Experiment window (containing the sequence of blocks) and Block window (containing the number of trials for each template within the block). In general, one "trial" of each block of trials is used to present instructions; reaction time data from the remaining trials of each block are recorded for later analysis.

"defensive" high self-esteem) display more defensive behaviors, such as in-group bias and ethnic discrimination, and are also higher in narcissism (Jordan, Spencer, \& Zanna, 2005; Jordan, Spencer, Zanna, Hoshino-Browne, \& Correll, 2003). Implicit measures also minimize problems associated with biased or socially desirable responding. For instance, whereas members of collectivist cultures such as those of China and Japan tend not to display a self-enhancement bias on explicit self-esteem measures, they do tend to show an implicit positivity bias favoring the self (Kitayama \& Karasawa, 1997).

\section{The Self-Esteem IAT}

Several measures have been developed to assess implicit self-esteem, but not all are equally reliable or predictive (Bosson, Swann, \& Pennebaker, 2000). Of these, the most reliable and valid measure of implicit self-esteem is the IAT (Bosson et al., 2000). The Self-Esteem IAT assesses implicit self-esteem by measuring the ease with which individuals associate the self with positive versus negative words.

As illustrated in Table 1, the Self-Esteem IAT is made up of seven categorization tasks, each as a separate block of trials (as discussed in Greenwald \& Farnham, 2000). In each case, a series of words appears in the center of the screen, and the participant must press either the " $\mathrm{d}$ " or "k" key as quickly as possible to categorize the word as belonging to one of two categories, which are displayed in the upper left and upper right of the screen. Errors are always followed by a red " $X$ " on the screen; the stimulus word remains on the screen until the correct response is made. The computer records reaction times and response accuracy.

In the first block, participants practice a target categorization task by categorizing a series of words into either a "self" category (me, self, my, mine) or an "other" category (others, them, they, theirs). Thus, the words "self" and "other" appear at the top of the screen, one word on each side. The stimulus words appear in the middle, one at a time. In the second block, participants practice an attribute categorization task by categorizing a series of words into either a "positive" category (worthy, loveable, valuable, admirable) or a "negative" category (inferior, unlovable, inadequate, undesirable). Again, the words "positive" and "negative" appear at the top of the screen, one word on each side, while the stimulus words appear one at a time in the middle. In the third and fourth blocks, participants practice and then are tested on a combined categorization task, in which they press one key for "self" or positive words and a different key for "other" or negative words. In this test block, the words "self" and "positive" appear at the top of one side of the screen, and the words "other" and "negative" appear at the top of the other side. Again, the stimulus words appear one at a time in the middle of the screen. In the fifth block, participants again practice a single categorization task for target words. However, this time the keys assigned to the words are reversed to prepare participants for a combined categorization task in which the target-attribute pairings are also reversed. To minimize the influence of the previously learned key assignments, participants are asked to perform more trials of this second single categorization task (see Table 1 for number of trials in each block). Finally, in the sixth and seventh blocks, participants practice and are tested on the reversed combined categorization task, this time pressing one key for "self" or negative words and a different key for "other" or positive words. Participants with high implicit self-esteem are slower to categorize words when self is paired with negative attributes than when it is paired with positive ones (Greenwald \& Farnham, 2000).

\section{The PsyScope Program}

The Self-Esteem IAT can be adapted for use on Macintosh computers via the PsyScope program (Bonatti, n.d.; Cohen et al., 1993). PsyScope is a Macintosh-based computer program used to present visual stimuli in different formats and locations across the computer screen. PsyScope represents experimental script instructions hierarchically using a graphic user interface. At the highest level of organization, the psi $(\Psi)$ icon represents the Experiment window, which displays the overall structure of the experiment (see Figure 1). Opening this window enables one to view the number and order of blocks in the experiment, as well as the number of trials within each block (see Figure 2). Each block can contain several templates. A template defines the order in which events (e.g., experimental instructions, presentation of stimuli, 


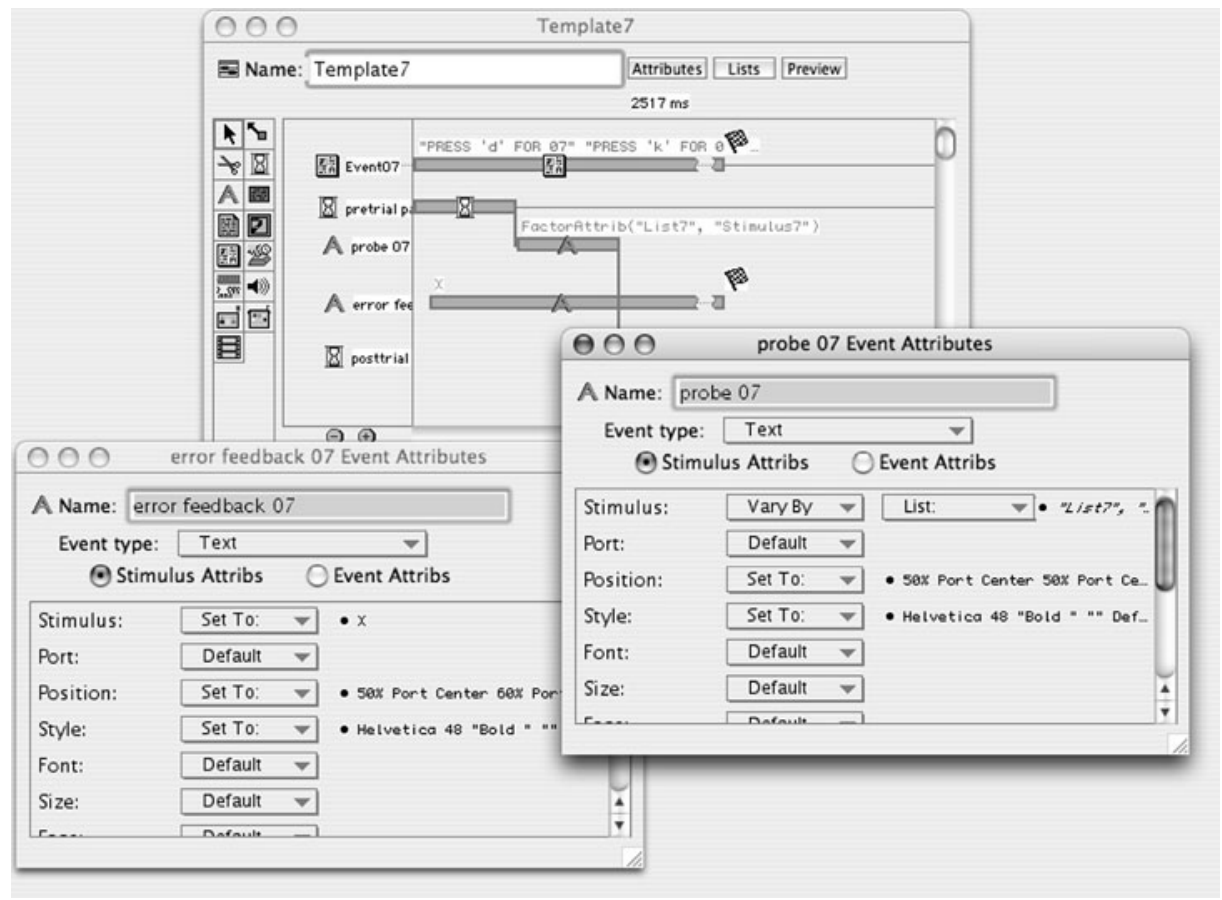

Figure 3. Clockwise, starting at top: Template window for an IAT block, Attributes window for the stimulus events, and Attributes window for the error events.

intertrial intervals) occur. Within each template, the user can adjust the attributes for both the events (e.g., duration of presentation, pretrial and posttrial pauses, keypresses, error feedback; see Figure 3) and the stimuli (e.g., font, size, color, pictures, position on screen; see Figure 4). The user can choose to define stimulus attributes within the program itself or by writing a plain text (.txt) file that can be linked to the experimental script (see Figure 5). Via the latter method, one can easily edit stimulus lists by editing a plain text file and then relinking it to the PsyScope script.

\section{Programming PsyScope to Run the Self-Esteem IAT}

To write an experimental script, the user selects the block icon. Within that block, the user needs two templates: one for the instructions and one for the stimulus presentation. In the IAT, prior to each block of trials, the instructions and the category labels are displayed on the screen simultaneously, to allow the participant to learn the location of the category labels. This presentation can be accomplished in the instruction template via the use of the Pasteboard feature, a screen image in which multiple stimuli can be presented simultaneously (see Figure 6). Moreover, the pasteboard can also serve as a continuous background layer for the presentation of stimuli. A pasteboard can therefore be used in the stimulus presentation template to display category labels. In this way, the user can continually see the category labels at the top of the screen while performing the categorization task.

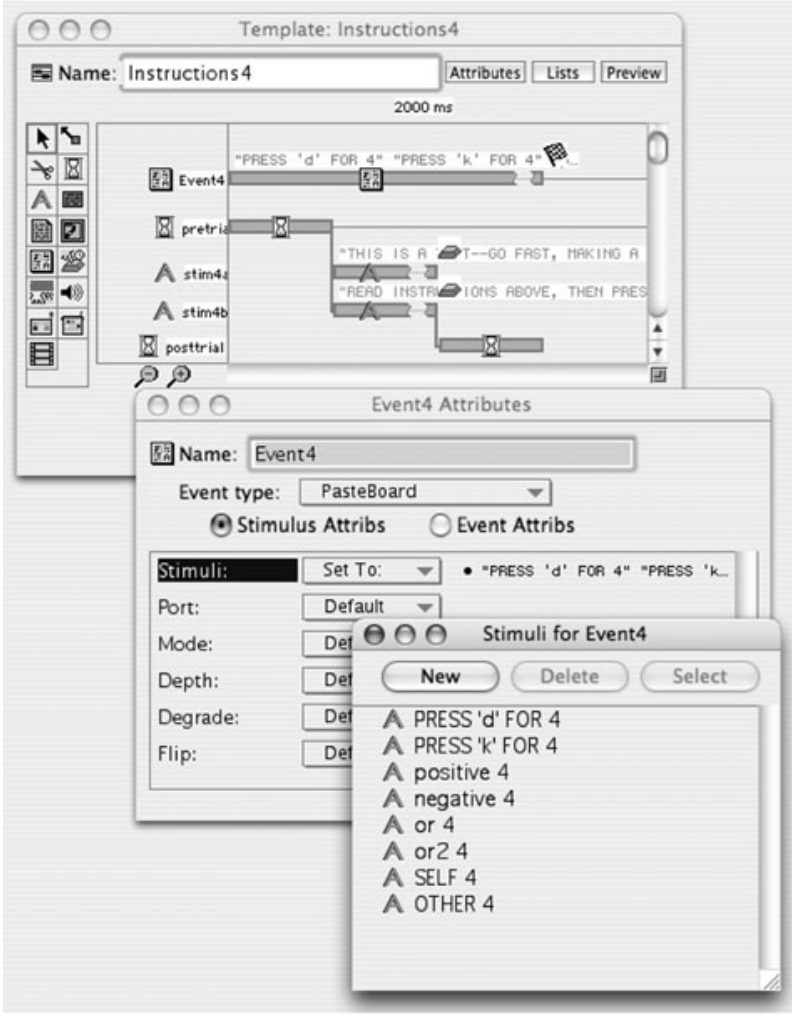

Figure 4. From back to front: Template window for an instructions display, Attributes window for the pasteboard layout, and Attributes window to define stimulus characteristics. 


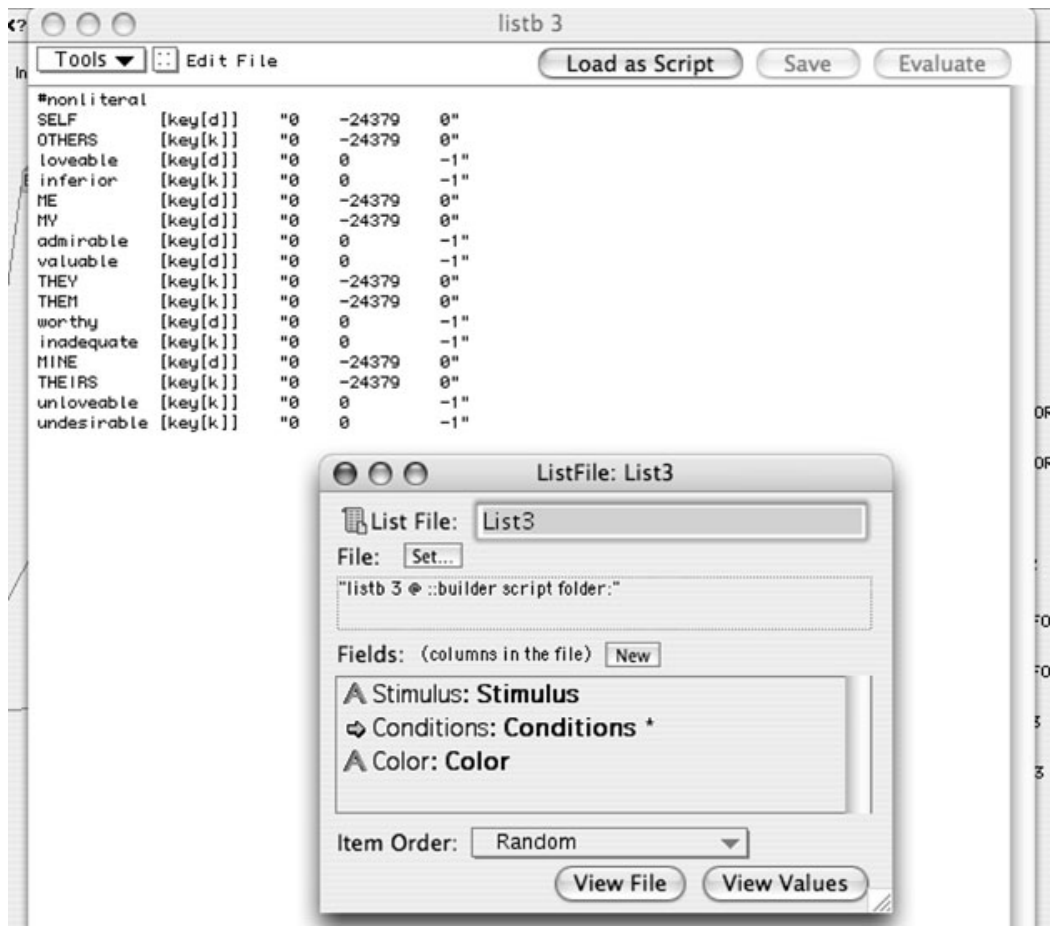

Figure 5. From back to front: Text file to define the stimulus list and list specification information window.

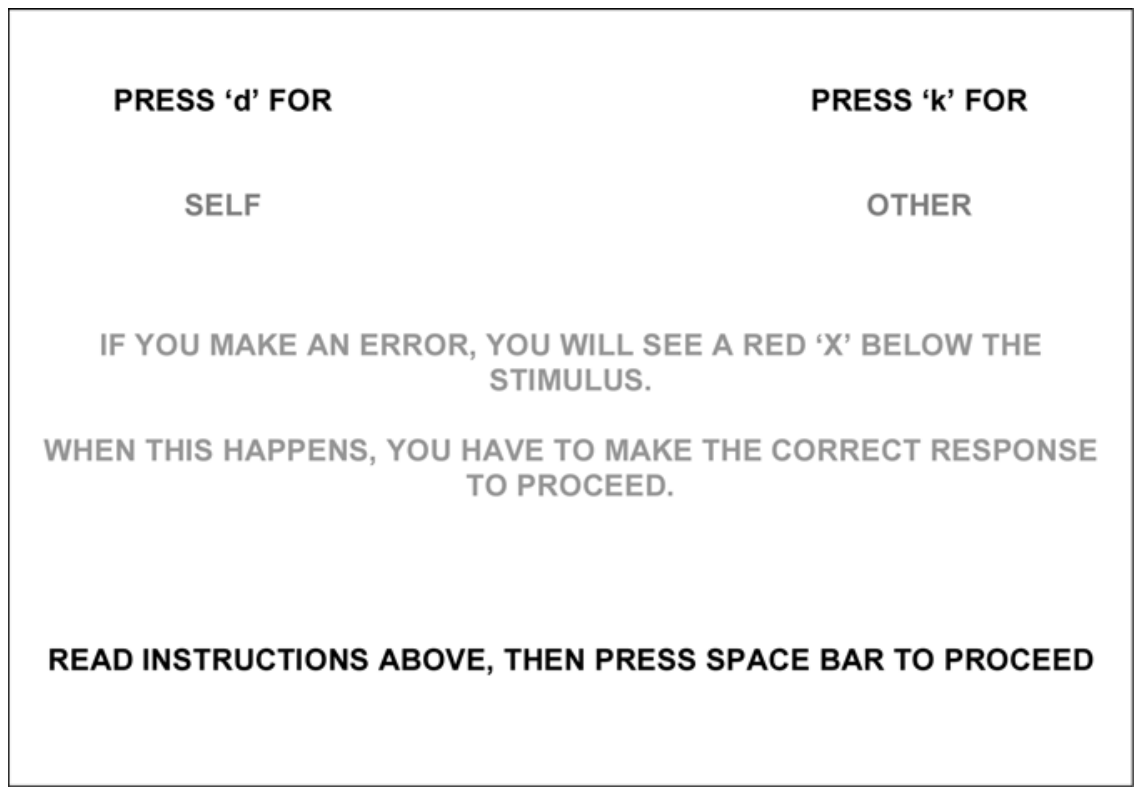

Figure 6. Pasteboard with instructions and preview of category labels.

In addition to the pasteboard for category labels, the template for stimulus presentation contains information about the stimuli and error response feedback. The stimuli are defined in an external text file. Within the text file, the user can specify stimuli, along with their corresponding correct response keys and any other stimulus attributes (e.g., font, size, color). The user can also program the script to display error feedback for any length of time. In the present script, the feedback (a red "X") remains on the screen until the correct response is made.

To avoid having the results confounded by practice, the experimenter can counterbalance the order of the two combined categorization tasks by making two script variants (A and B) and administering each to half the partici- 


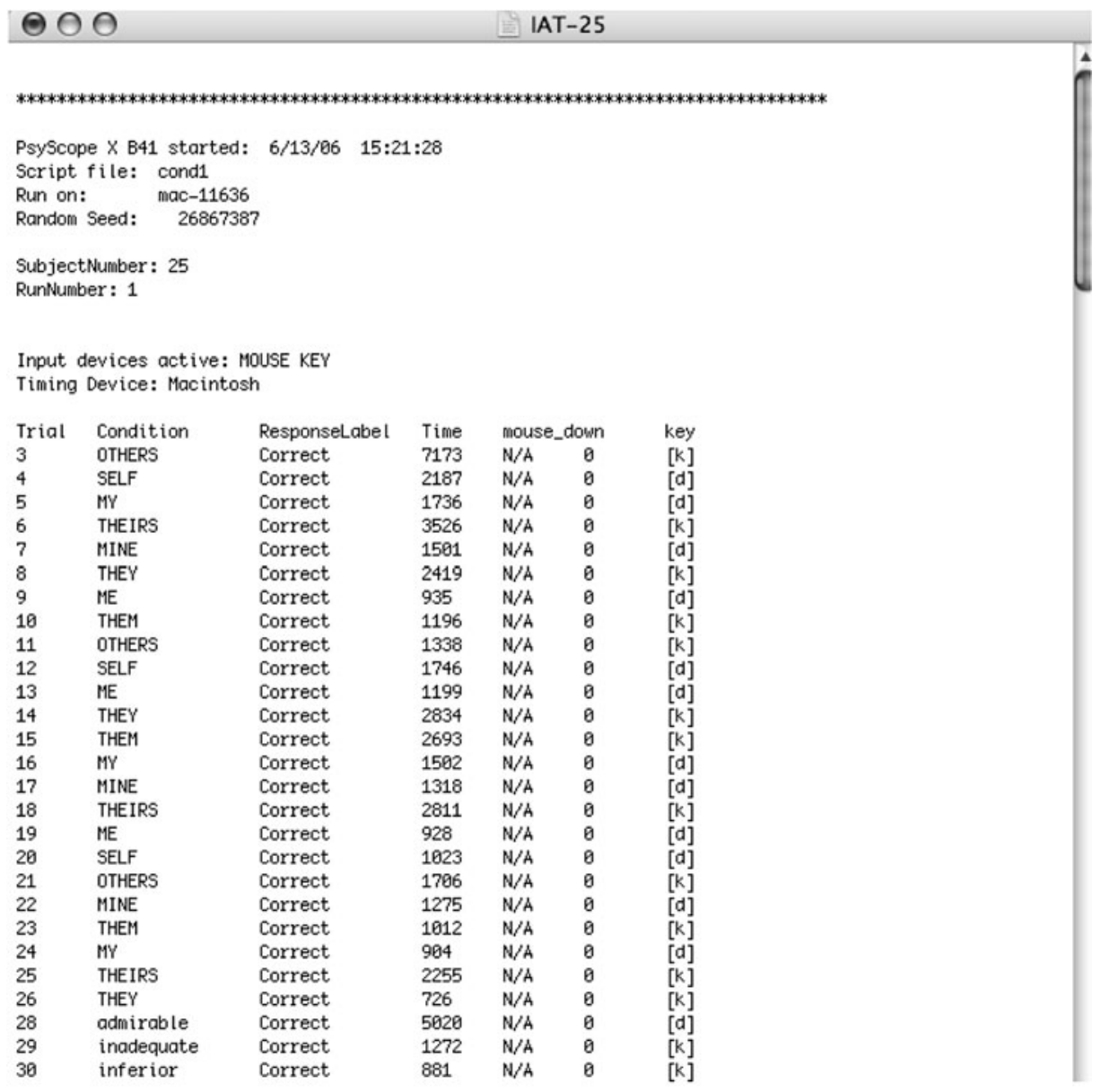

Figure 7. Sample PsyScope data file showing the first 30 trials of Participant 25's data.

pants. In Script Variant A, the block order is as illustrated in Table 1, in which the self-positive/other-negative combined categorization task (Blocks 3 and 4) is followed by the self-negative/other-positive combined categorization task (Blocks 6 and 7). In Script Variant B, the order of these critical blocks and their associated practice blocks is reversed (see note of Table 1).

\section{Translating PsyScope Data Files to SPSS Format}

PsyScope saves the data from each participant (individual reaction times and accuracy for each trial's response) as a separate tab-delimited text file, in which each row represents one response (see Figure 7 for a sample data file). To make the data files importable, the user must delete all text in each file prior to the line containing the variable labels. The easiest way to import the data into SPSS is to open a PsyScope data file from within SPSS and use the "Text Import Wizard" to define the variables. One can then paste this syntax and copy it for the remaining data files, editing the syntax so that it identifies each individual data file. Once the syntax file is run and the SPSS files are merged, the data are ready to be analyzed via the proce- dures outlined by Greenwald and colleagues (Greenwald et al., 1998; Greenwald, Nosek, \& Banaji, 2003).

Alternatively, the process of setting up the data for SPSS analysis can be automated. We have provided a sample SPSS syntax file (downloadable from psychonomic .org/archive) that eliminates the need to edit the data files prior to importing them. Our syntax file includes compute statements following each participant's data to define the subject number and counterbalancing order. It creates an individual SPSS data file for each participant (see Figure 8), then merges these files into an aggregate file in which the data from each participant are represented as a single row. Per Greenwald and colleagues (Greenwald et al., 1998; Greenwald et al., 2003), the syntax file specifies that reaction times greater than 3,000 msec and shorter than $300 \mathrm{msec}$ are recoded as 3,000 and $300 \mathrm{msec}$, respectively. In addition to providing mean reaction times for each block, the syntax file computes the IAT score by subtracting the mean reaction time for the self-positive/ other-negative test block (Block 4 in Table 1) from the mean reaction time for the self-negative/other-positive test block (Block 7 in Table 1) and taking the natural loga- 


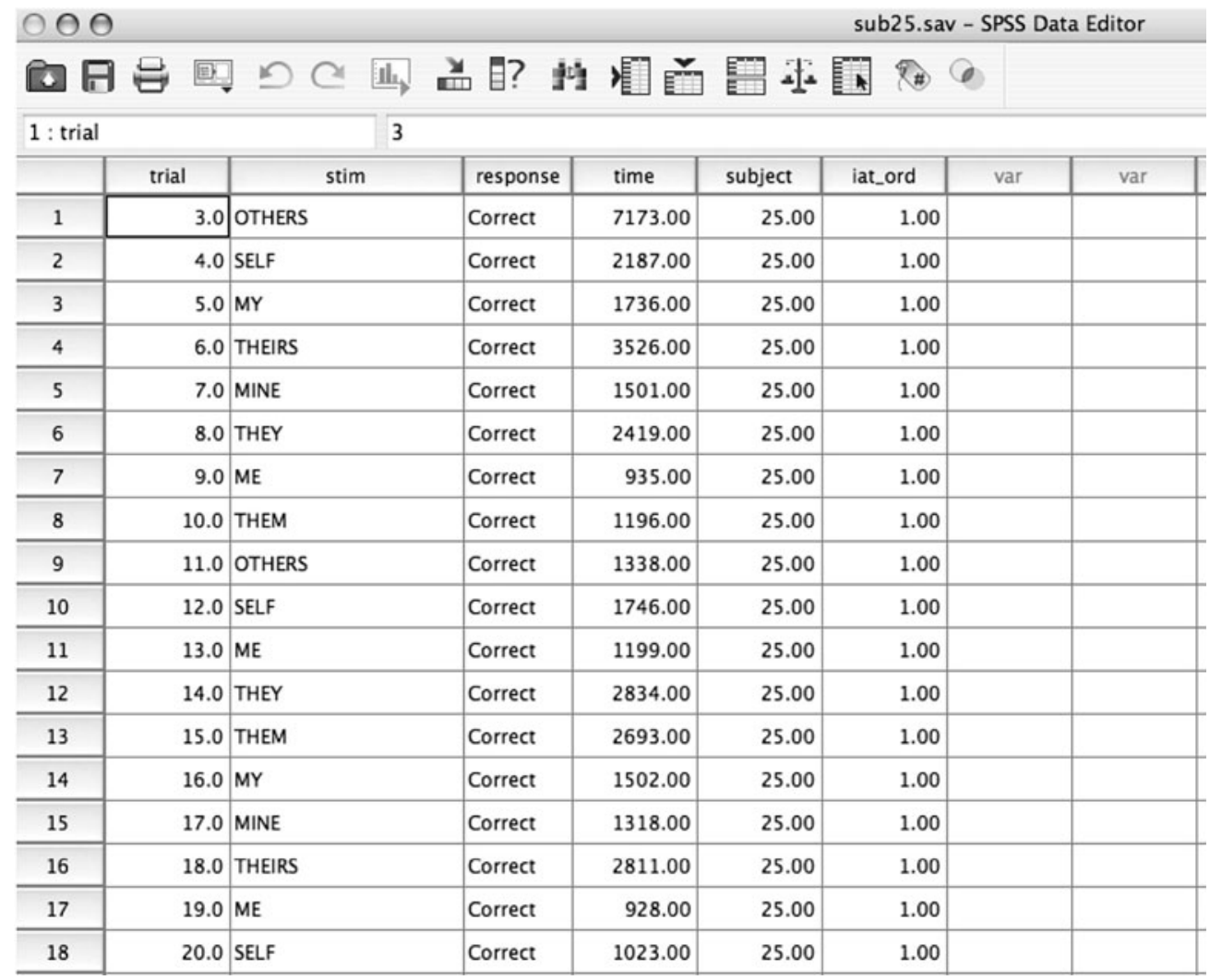

Figure 8. Sample SPSS data file showing the first 20 trials of Participant 25's data. These individual data files are then merged (using a syntax file) to create the aggregate data file, which includes one row per participant.

rithm of the result to normalize the distribution. Higher numbers represent higher implicit self-esteem. The untransformed data (in msec) are retained as variables in the file for use in constructing graphs. The synt ax file also computes an IAT error score by subtracting the number of errors made in the compatible block (i.e., Block 4) from the number of errors made in the incompatible block (i.e., Block 7). Finally, the syntax file computes the $D$ measure recommended by Greenwald and colleagues (see Greenwald et al., 2003, for an explanation).

\section{Sample Study Using the PsyScope Self-Esteem IAT}

As an initial check of the PsyScope Self-Esteem IAT, we conducted a study in which 78 college-age participants (35 men, 43 women) took the IAT along with several measures of explicit self-esteem. ${ }^{1}$ Orders of the implicit and explicit measures were counterbalanced, as was the order of the combined test blocks. Consistent with previous research using the Self-Esteem IAT (Greenwald \& Farnham, 2000; Karpinski, 2004), participants preferred "self" $(M=725 \mathrm{msec}, S D=152 \mathrm{msec})$ to "other," $(M=$ $879 \mathrm{msec}, S D=200 \mathrm{msec})$; that is, they responded more quickly on the self-positive and other-negative trials than on the self-negative and other-positive trials. The mean difference of $154 \mathrm{msec}$ was significantly different from zero by a one-sample $t$ test $[t(77)=8.16, p<.001]$.
We also included three questionnaire measures of explicit self-esteem: an 8-item measure of feelings of selfworth (Brown \& Dutton, 1995), a 10-item measure of self-evaluation (Brown \& Dutton), and the 20-item State Self-Esteem Scale (Heatherton \& Polivy, 1991). All measures used a 5-point rating scale from "not at all" to "extremely." We counterbalanced the order of the implicit and explicit self-esteem measures. Correlations between the IAT and the explicit measures ranged from $r=.14$ to $r=$ .25 . These correlations are similar to those found in previous research (Greenwald \& Farnham, 2000), indicating a small but positive relation between implicit and explicit self-esteem.

\section{Summary}

We have described a means of running IAT studies on Macintosh computers using the PsyScope program. Our preliminary results were similar to those obtained using the PC version of the Self-Esteem IAT. In our estimation, the Macintosh version provides a comparable system for conducting IAT research and includes several useful features. First, researchers using the IAT will no longer be constrained to PC platforms. Second, PsyScope's graphic user interface makes it user-friendly; it is easy to visualize the design of the experiment. Third, the script can easily be edited to create any kind of IAT, not just SelfEsteem IATs. Fourth, the data can be directly imported 
from PsyScope data files into SPSS for further analysis. Finally, PsyScope for Macintosh OS X can be downloaded at no cost from psy.ck.sissa.it, making IAT research more widely accessible than was previously possible.

\section{AUTHOR NOTE}

This research was partially supported by fellowships to M.E.V.W. and T.A.Z. from the Ralph E. Hansmann Science Students Support Fund at Hamilton College. We thank Jonathan Vaughan for his helpful comments on drafts of this article. Correspondence concerning this article should be addressed to J. Borton, Department of Psychology, Hamilton College, 198 College Hill Road, Clinton, NY 13323 (e-mail: jborton@hamilton.edu).

\section{REFERENCES}

Banse, R., Seise, J., \& Zerbes, N. (2001). Implicit attitudes towards homosexuality: Reliability, validity, and controllability of the IAT. Zeitschrift für Experimentelle Psychologie, 48, 145-160.

Bonatti, L. (n.d.). Welcome to the PsyScope X info page. Retrieved August 15, 2006, from psy.ck.sissa.it

Bosson, J. K., Swann, W. B., JR., \& Pennebaker, J. W. (2000). Stalking the perfect measure of implicit self-esteem: The blind men and the elephant revisited? Journal of Personality \& Social Psychology, 79, 631-643.

Brown, J. D., \& DutTon, K. A. (1995). The thrill of victory, the complexity of defeat: Self-esteem and people's emotional reactions to success and failure. Journal of Personality \& Social Psychology, 68, 712-722.

Chambliss, H. O., Finley, C. E., \& Blair, S. N. (2004). Attitudes toward obese individuals among exercise science students. Medicine \& Science in Sports \& Exercise, 36, 468-474.

Cohen, J., MacWhinney, B., Flatt, M., \& Provost, J. (1993). PsyScope: An interactive graphic system for designing and controlling experiments in the psychology laboratory using Macintosh computers. Behavior Research Methods, Instruments, \& Computers, 25, 257-271.

Dasgupta, N., McGhee, D. E., Greenwald, A. G., \& Banaji, M. R. (2000). Automatic preference for White Americans: Eliminating the familiarity explanation. Journal of Experimental Social Psychology, 36, 316-328.

Farnham, S. D., Greenwald, A. G., \& Banaji, M. R. (1999). Implicit self-esteem. In D. Abrams \& M. A. Hogg (Eds.), Social identity and social cognition (pp. 230-248). Malden, MA: Blackwell.

Gawronski, B. (2002). What does the Implicit Association Test measure? A test of the convergent and discriminant validity of prejudicerelated IATs. Experimental Psychology, 49, 171-180.

Greenwald, A. G., \& Farnham, S. D. (2000). Using the Implicit Association Test to measure self-esteem and self-concept. Journal of Personality \& Social Psychology, 79, 1022-1038.

Greenwald, A. G., McGhee, D. E., \& Schwarz, J. L. K. (1998). Measuring individual differences in implicit cognition: The Implicit Association Test. Journal of Personality \& Social Psychology, 74, 1464-1480.

Greenwald, A. G., \& Nosek, B. A. (2001). Health of the Implicit Association Task at age 3. Zeitschrift für Experimentelle Psychologie, 48, 85-93.

Greenwald, A. G., NoseK, B. A., \& Banaji, M. R. (2003). Understanding and using the Implicit Association Test: I. An improved scoring algorithm. Journal of Personality \& Social Psychology, 85, 197-216.

Heatherton, T. F., \& Polivy, J. (1991). Development and validation of a scale for measuring state self-esteem. Journal of Personality \& Social Psychology, 60, 895-910.

Jelenec, P., \& StefFens, M. C. (2002). Implicit attitudes toward elderly women and men. Current Research in Social Psychology, 7, 275-293.

Jordan, C. H., Spencer, S. J., \& Zanna, M. P. (2005). Types of high self-esteem and prejudice: How implicit self-esteem relates to ethnic discrimination among high explicit self-esteem individuals. Personality \& Social Psychology Bulletin, 31, 693-702.

Jordan, C. H., Spencer, S. J., Zanna, M. P., Hoshino-Browne, H., \& Correll, J. (2003). Secure and defensive high self-esteem. Journal of Personality \& Social Psychology, 85, 969-978.

KARPINSKI, A. (2004). Measuring self-esteem using the Implicit Association Test: The role of the other. Personality \& Social Psychology Bulletin, 30, 22-34.

Kitayama, S., \& Karasawa, M. (1997). Implicit self-esteem in Japan: Name letters and birthday numbers. Personality \& Social Psychology Bulletin, 23, 736-742.

McConnell, A., \& Leibold, J. M. (2001). Relations among the Implicit Association Test, discriminatory behavior, and explicit measures of racial attitudes. Journal of Experimental Social Psychology, 37, 435-442.

Ottaway, S. A., Hayden, D. C., \& OAKes, M. A. (2001). Implicit attitudes and racism: Effects of word familiarity and frequency on the Implicit Association Test. Social Cognition, 19, 97-144.

Pinter, B., \& Greenwald, A. G. (2005). Clarifying the role of the "other" category in the self-esteem IAT. Experimental Psychology, 52, 74-79.

Rowatt, W. C., Franklin, L. M., \& Cotton, M. (2005). Patterns and personality correlates of implicit and explicit attitudes toward Christians and Muslims. Journal for the Scientific Study of Religion, 44, 29-43.

Rudman, L. A., Greenwald, A. G., Mellott, D. S., \& Schwartz, J. L. K. (1999). Measuring the automatic components of prejudice: Flexibility and generality of the Implicit Association Test. Social Cognition, 17, 437-465.

Spalding, L. R., \& Hardin, C. D. (2000). Unconscious unease and selfhandicapping: Behavioral consequences of individual differences in implicit and explicit self-esteem. Psychological Science, 10, 535-539.

Teachman, B. A., Gapinski, K. D., Brownell, K. D., Rawlins, M., \& Jeyaram, S. (2003). Demonstrations of implicit anti-fat bias: The impact of providing causal information and evoking empathy. Health Psychology, 22, 68-78.

Wang, S. S., Brownell, K. D., \& Wadden, T. A. (2004). The influence of the stigma of obesity on overweight individuals. International Journal of Obesity, 28, 1333-1337.

\section{NOTE}

1. Prior to completing the IAT, participants were randomly assigned either to suppress or not suppress their most negative thought about themselves. Discussion of these results, which will be reported in detail elsewhere, is beyond the scope of the present article.

\section{ARCHIVED MATERIALS}

The following materials may be accessed through the Psychonomic Society's Norms, Stimuli, and Data Archive, www.psychonomic.org/ archive. To access these files, search the archive for this article using the journal (Behavior Research Methods), the first author's name (Borton), and the publication year (2007).

FiLE: Jennifer_Borton-BRMIC-2007.zip

DESCRIPTION: The compressed archive file contains eight files:

Self-Esteem IAT Script.txt, containing a PsyScope script for running a Self-Esteem Implicit Association Test;

Six lists for the PsyScope script: Listb1.txt, listb2.txt, listb5.txt, listb8 .txt, listb9.txt, and listb10.txt;

IATsyntax.sps, containing an SPSS syntax file for reading the PsyScope data into SPSS and analyzing the data according to the Greenwald et al. (1998; Greenwald et al., 2003) protocol.

AUTHOR's E-MAIL ADDRESS: jborton@hamilton.edu

(Manuscript received August 24, 2006; revision accepted for publication September 20, 2006.) 